\title{
Myopia in Singapore: taking a public health approach
}

Benjamin Seet, Tien Yin Wong, Donald T H Tan, Seang Mei Saw, Vivian Balakrishnan, Lionel K H Lee, Arthur S M Lim

Defence Medical

Research Institute,

Singapore

B Seet

L K H Lee

Medical Classification

Centre, Singapore

Armed Forces,

Singapore

B Seet

Singapore National

Eye Center and

Singapore Eye

Research Institute,

Singapore

T Y Wong

D T H Tan

V Balakrishnan

A S M Lim

Department of

Ophthalmology,

National University of

Singapore, Singapore

T Y Wong

D T H Tan

V Balakrishnan

A S M Lim

\section{Department of}

Community,

Occupational and

Family Medicine,

National University of

Singapore, Singapore

S M Saw

Headquarters of the

Singapore Armed

Forces Medical Corps,

Singapore

L K H Lee

Correspondence to:

Tien Yin Wong, FRCS(Ed), $\mathrm{MPH}$, Department of

Ophthalmology, National

University of Singapore, 10

Kent Ridge Crescent,

Singapore 119260

tienyinwong@yahoo.com

Accepted for publication

4 January 2001
Myopia is a problem of public health concern in Singapore for three reasons. Firstly, the prevalence of myopia (more than -0.5 dioptres (D)) is one of the highest worldwide. Twenty per cent of Singapore children are myopic at 7 years at the start of their primary education, ${ }^{1}$ with prevalence exceeding $70 \%$ upon completing college education..$^{2-4}$ Other population based studies showed myopia prevalence of $15 \%$ in preschool 4 year old children, ${ }^{5} 80 \%$ in military conscripts, ${ }^{6}$ and nearly $40 \%$ in adult Chinese aged 40 and older. ${ }^{7}$ This is $1.5-3$ times higher than similarly aged white or black populations in the United States, ${ }^{8-10}$ and elsewhere. ${ }^{11} 12$

Secondly, a large proportion of Singaporeans has high myopia (more than $-6.0 \mathrm{D}$ ), which has been observed across the whole age spectrum. ${ }^{167}$ While the prevalence of high myopia is less than $2 \%$ in most Western populations, ${ }^{10} 11$ approximately $10 \%$ of Singapore adults have the condition. ${ }^{67}$

Thirdly, available data suggest that both prevalence and severity of myopia have increased significantly over the past two decades. Based on serial cross sectional data from the Singapore Armed Forces, myopia prevalence in military conscripts has increased from $26 \%$ in the late 1970 s, to $43 \%$ in the 1980 s, $66 \%$ in the mid 1990 s, and $83 \%$ by the late 1990 s. ${ }^{6}{ }^{13} 14$ This is accompanied by a twofold rise in the proportion with myopia worse than $-8 \mathrm{D}$, from $2 \%$ to $4 \%$ between 1993 and $1997 .{ }^{4}$ A similar trend of increasing myopia prevalence has been observed in schoolchildren. ${ }^{15}$

The underlying explanation for high myopia prevalence and severity in Singapore is not well understood. Available data suggest that this phenomenon is not unique to Singapore. A high prevalence of myopia has also been described in other east Asian urban populations in Taiwan, Hong Kong, and Japan. ${ }^{16-20}$ In Taiwan, a substantial increase in the prevalence of myopia in schoolchildren has similarly been observed over the past few decades, ${ }^{16}{ }^{17}$ although in Japan, the rates may have tapered somewhat. ${ }^{820}$ Furthermore, sociodemographic risk factors for myopia in these populations appear to be similar to those reported in the West, and include higher education, higher income, and occupations associated with near work activities..$^{6-8}$ It is therefore likely that complex and multiple factors, both genetic and environmental, are involved.

In this paper, we systematically examine the impact of myopia in Singapore, propose a model to explain its high prevalence in the population, and outline a strategy for myopia control.

\section{Defining the impact of myopia in Singapore}

THE MEDICAL PERSPECTIVE

There is concern that blindness from myopia will become a substantial public health problem in the near future. With an ageing population (more than one third of Singaporeans will be older than 50 years by $2025^{21}$ ), and a rising trend of myopia prevalence and severity, ${ }^{41314}$ it has been projected that more than $80 \%$ of the entire adult population could be myopic within two to three decades, with a significant proportion having high myopia. Although low and moderate myopia appears to be more benign, high myopia may be associated with posterior vitreous detachment, ${ }^{22}$ myopic macular degeneration, ${ }^{23-25}$ peripheral retinal breaks, degeneration and retinal detachment, ${ }^{26}$ and possibly glaucoma ${ }^{27}$ and reduced contrast sensitivity. ${ }^{28} 29$

Nevertheless, the potential impact of myopia on blindness rates in the population is not clear. Data from blindness registry paint a gloomy picture, but are subjected to many sources of bias (for example, low participation rate, inaccuracies in diagnosis). For example, in Germany, which has relatively low myopia prevalence, $12-17 \%$ of blindness is reportedly attributed to high myopia. ${ }^{30}$ In Denmark, 5\% of registered blindness is related to myopia. ${ }^{31}$ Similarly, in Singapore, blindness registry data indicate that myopia is the fourth leading cause of blindness. ${ }^{32}$ However, population based prevalence survey data in the United States suggest that myopia is not a leading cause of either visual impairment ${ }^{33}$ or blindness $^{34}$ in adults, although the rates of myopia are lower in the US population. ${ }^{10}$ Thus, the full medical implications of a high myopia prevalence in Singapore are not known at this time.

\section{THE PUBLIC PERSPECTIVE}

Historically, the Singapore public did not perceive myopia as a serious problem. There were no associated social stigmata, while the wearing of spectacles may even be regarded as a norm in most Singapore schools. Ocular complications affected only a small proportion of individuals with severe myopia, with the majority experiencing little or no vision related problems. However, this attitude may be changing. Parents have been more vocal in expressing concern about the early onset of myopia in children, ${ }^{35}$ while many are seeking a "quick fix" to myopia prevention. ${ }^{36} 37$ Greater media attention on myopia has 
increased political awareness, which has led to sustained research funding for myopia in Singapore.

THE EDUCATION PERSPECTIVE

The high myopia prevalence among Singapore schoolchildren is a particular problem. ${ }^{138}$ The consistently strong evidence of an association between myopia and education ${ }^{7-12}$ has raised concerns that the rapid rise in myopia prevalence may be related to higher educational attainment among Singaporeans. ${ }^{2639}$ However, whether myopia is related to education or to other socioeconomic factors (for example, urbanisation) is still unclear. For example, in a study of comparable schoolchildren aged 7-8 years, the myopia rate in Singapore Chinese (many originating from south China) was higher than in the city of Xiamen in south China. ${ }^{40}$

THE MILITARY PERSPECTIVE

National military service is required for all Singapore men. From the military perspective, myopia is important for various reasons. Firstly, correction with spectacles or contact lenses may be incompatible with the stringent occupational demands of many military vocations. ${ }^{41}$ Spectacles cause interface problems with binoculars, night vision devices, protective masks, and other head mounted instruments. Determining a refractive error cut off for personnel selection has therefore been problematic, with conflicting requirements of meeting recruitment levels and maintaining high visual standards as a selection criterion. ${ }^{42} \mathrm{At}$ the Republic of Singapore Air Force, almost $20 \%$ of military pilot applicants are rejected based solely on refractive status. ${ }^{43}$ Secondly, spectacle replacement presents a logistic problem in military field operations. For example, there is need for updated and customised refraction records of all myopic soldiers, and constant availability of optometry services. ${ }^{41}$ Finally, there is a perception that myopia affects performance in visually demanding tasks like military aviation and marksmanship, although this remains unproved. Decreased contrast sensitivity at high spatial frequencies has been reported with increasing myopia severity, ${ }^{28}{ }^{29}$ and lower contrast sensitivity is associated with impaired perception of "real world targets, ${ }^{\prime 44}$ poorer flight performance in aircraft simulators, ${ }^{45}$ and deficits in visualspatial attention. ${ }^{46}$ Few data on the direct association between myopia and military performance exist. Available studies have not found an association between myopia and shooting performance or military aviation. ${ }^{47} 48$ A similar project in the Singapore military failed to detect significant differences in marksmanship scores between myopic and emmetropic soldiers (B Seet, unpublished data, 1999).

THE ECONOMIC PERSPECTIVE

In Singapore, direct costs related to the correction of myopia, including refractive eyewear and surgery, is expected to increase. In 1998, there were 816 optical outlets in Singapore, or one outlet for every 3800 people. ${ }^{21}$ It has been estimated that myopic Singaporeans spend \$US90 million annually on spectacles alone. ${ }^{21}$ Refractive surgery has become increasingly popular in Singapore, with the number of excimer laser machines increasing from one in 1992 to eight in 2000. Refractive surgery is now the second most common procedure after cataract surgery, performed at a cost of about $\$ 3$ million annually. ${ }^{49}$

There are also indirect costs related to treatment of myopia related complications, estimated at \$2-2.5 million annually. About 300 retinal detachments are operated on each year (although not all are attributable to myopia), ${ }^{50}$ and about 800 contact lens complications, including 80 cases of severe corneal ulcers, are treated at public hospitals (DTH Tan, unpublished data, 2000). In fact, contact lens wear is the main risk factor for corneal ulcers in Singapore. ${ }^{51}$ Additional indirect costs are incurred by ongoing myopia research in Singapore, estimated to be \$2-3 million annually. ${ }^{52}$ Thus, there is a strong economic incentive to find an effective solution to myopia in Singapore.

\section{Determinants of high myopia prevalence in Singapore}

Despite extensive research, the aetiology remains unknown. It is discussed in detail elsewhere. ${ }^{85-55}$ In this paper, we offer a three tier model of potential determinants of the high myopia prevalence in Singapore (Fig 1), based on a public health approach. This model forms the basis for several myopia intervention strategies described in the next section.

PROXIMAL FACTORS: GENETICS AND MOLECULAR BIOLOGY OF MYOPIA

Myopia has been postulated to arise from an underlying genetic predisposition that makes the eye more susceptible to environmental modification of its growth. ${ }^{5657}$ The relative contribution of genes (nature) versus environment (nurture) has been the subject of intense debate, and is probably complex..$^{54-56}$ For example, the high prevalence of myopia in Singapore and east Asia, compared with similarly aged white and black populations in other countries, may be related to ethnic variations in either genetic or environmental exposures. ${ }^{58}$ However, several lines of evidence point to a strong genetic role. Variation in genetic exposure has been suggested as explaining differences in education adjusted myopia prevalence between young adult Chinese, Indians, and Malays in Singapore. ${ }^{614}$ In Singapore military conscripts, there is a strong association of myopia and parental history of myopia (odds ratio of 3.6 for myopia, 5.2 for high myopia), as well as sibling history of myopia (odds ratio of 8.6 for myopia, 14.4 for high myopia). ${ }^{4}$ In other east Asian populations, data from twin studies show significantly greater intrapair variance in refractive error among dizygotic compared with monozygotic twins. ${ }^{50}$ Data from the 


\section{Distal factors \\ Urbanisation 2140 \\ Extensively built up with limited outdoor space \\ Confined living environment and "visual space" \\ Meritocracy 1217576 \\ National policy promoting human resource development \\ Knowledge based economy \\ High emphasis on education}

important molecular roles in the causation of myopia. $^{6667}$

INTERMEDIATE FACTORS: ENVIRONMENT RISK FACTORS FOR MYOPIA

In support of the "environmental" contribution of myopia, studies have shown earlier age of myopia onset in similar populations over time ${ }^{17} 20$; higher myopia prevalence in younger compared with older cohorts ${ }^{1868}$; and weaker sibling association with myopia with increasing sibling age difference. ${ }^{68}$ In east Asia, increasing prevalence of myopia has been attributed to changing "environmental" conditions over the past three generations. ${ }^{69}$ Some of these factors in Singapore include having higher education, ${ }^{26739}$ near work related occupations, ${ }^{70}$ and greater family income. ${ }^{7}$ However, the exact relation between near work activity and development or progression of myopia remains to be established, ${ }^{71}$ partly because quantification of near work is problematic. ${ }^{55} 727374$

\section{DISTAL FACTORS: SOCIETAL INFLUENCE ON} MYOPIA

Largely ignored, distal factors may also be important in determining the rate of myopia in a given population. Singapore is an urban city state with a population of 3.8 million and a population density of almost 15000 per square mile. ${ }^{21}$ Ninety per cent of the population live in high rise apartments less than 1300 square feet in area, with a household average of 2.5 people per room. ${ }^{21}$ The people lead primarily indoor lifestyles, owing to the relative lack of large open public spaces. However, although similar trends in myopia rates are seen in Taiwan, a large proportion of their population does not live in such conditions. Thus, whether the macroenvironment plays an important part in influencing the visual cues in developing eyes remains unclear. ${ }^{54}$

In addition, Singapore has also been described as a highly competitive society, with great emphasis placed on educational achievements in determining career choices and advancement. This is evident in public policies that have focused on developing the human resource to serve a knowledge based economy. ${ }^{75}{ }^{76}$ Societal trends over the past three decades include the early "streaming" of schoolchildren within the education system; the increasing proportion of Singaporeans, particularly females, attaining higher education; and the increasing participation of females in wage earning employment. ${ }^{21}$ Similar social changes are seen in other countries like Taiwan, Hong Kong, and Japan. It is also possible that some of these factors are important in explaining the high myopia prevalence in east Asia.

Approach to myopia control in Singapore Since the increasing prevalence of myopia was noted in the late 1980s, various agencies, including the ministry of health, school health services, and ministry of defence, have raised concerns about the condition. ${ }^{141338}$ However, early efforts to control myopia were largely institution based, lacking the mandate and 
resources to manage the problem at the national level. This led to the formation of a multiagency National Committee on Myopia in the late 1990s, with objectives to formulate strategies to prevent and control myopia, as well as to centrally plan myopia research in Singapore. Such a committee ensures focus, integration, and sustainability of local efforts to manage the myopia problem. Increased public concern has also been critical in determining political interest and funding for myopia research.

\section{THE VISION CARE PROGRAMME}

There are presently a number of options for myopia prevention and control. ${ }^{87}$ Many of these are directed at proximal factors, including topical eyedrops like atropine, ${ }^{78}$ optical lenses, ${ }^{79} 80$ rigid contact lenses, ${ }^{81}$ intraocular pressure lowering agents, ${ }^{82}$ biofeedback methods, ${ }^{83}$ and traditional techniques like Chinese "eye relaxation" exercises. ${ }^{84}$ However, the effectiveness of some of these methods is questionable, and there is inadequate scientific evidence for implementation in a population setting. Many clinical trials lacked randomisation, had high dropout rates, or failed to account for confounding. ${ }^{8}$ On the other hand, it is difficult to prescribe interventions to reduce exposure to either intermediate or distal factors like education, near work, and living conditions.

In the absence of definitive interventions, a broad "vision care programme" was initiated in Singapore schools. ${ }^{85}$ This is largely based on existing evidence that prolonged near work (and possibly poor visual environment) may contribute to myopia onset and progression, and on the hypothesis that relieving eye strain and promoting visual health will have beneficial effects. This programme comprises annual vision screening in schoolchildren, appropriate refractive correction, "eye relaxation" techniques, promotion of outdoor activities, and guidelines on classroom materials and illumination. An emphasis is placed on educating schoolchildren, parents, and teachers on general eye care, good reading habits, and myopia. The next phase of the programme is to combine these with clinical trials involving pharmacological and optical interventions, ${ }^{78-81}$ or even controversial techniques like "eye relaxation" exercises. ${ }^{84}$ This programme is intended to evolve as our knowledge of myopia increases.

\section{PUBLIC EDUCATION AND CLINICAL PRACTICE}

GUIDELINES

The inconsistent results of current myopia treatment have generated confusion in an anxious population. The ministry of health has made efforts to conduct regular public forums, health fairs, and community based eye screening programmes in Singapore. To prevent excessive use and abuse of putative myopia treatment modalities, clinical practice guidelines are also issued to establish clear indications and limitations of contact lens ${ }^{86}$ and laser refractive surgery, ${ }^{87}$ in the management of myopia.
MYOPIA RESEARCH IN SINGAPORE

The goal of myopia research in Singapore lies in developing "practical" approaches that will ultimately modify the biological course of the condition, ideally to prevent the onset of myopia altogether. In line with this, basic science research is directed towards identifying genetic markers of myopia, ${ }^{64}$ understanding cellular pathways of emmetropisation, ${ }^{88}$ and developing animal models for clinical trials. Clinical research is centred on randomised trials to prevent or slow myopia progression (topical eye drops, rigid contact lenses), ${ }^{81}$ and to correct myopia (refractive surgery trials) ${ }^{87}$ Epidemiological studies evaluate putative risk factors of myopia in schoolchildren ${ }^{15}{ }^{71}$ military personnel, ${ }^{46}$ and adults. ${ }^{789}$ Finally, additional research in the military evaluates visual performance in myopes, ${ }^{29}{ }^{30}$ developing functional visual criteria for personnel selection, ${ }^{4}$ and optimising visual function for myopes under different operational settings. ${ }^{90}$

\section{Conclusion}

The prevalence of myopia in Singapore is one of the highest worldwide. Current data indicate that both the rate and severity of myopia may be increasing over time. A similar epidemic appears to be occurring in other east Asian populations, and it is possible that ocular morbidity related to myopia may constitute an important clinical, public health, and economic problem over the next two to three decades. Because knowledge about myopia is incomplete and potential therapeutic measures have yet to be proved consistently effective, a pragmatic public health approach has been adopted in Singapore, comprising a "vision care" programme in schools, regular public education, and an integrated myopia research strategy.

Dedication

The authors dedicate this paper in memory of the late Sek Jin Chew, FRCS, PhD, (1959-98), who had been one of the driving forces behind myopia research in Singapore and internationally.

1 Rajan U, Tan FT, Chan TK, et al. Increasing prevalence of myopia in Singapore school-children. In: Chew SJ, Weintraub J, eds. Proceedings of the 5th International Conference on Myopia; 1994 22-24 fune; Toronto. New York: Myopia International Research Foundation, 1995:41-46.

2 AuEong KG, Tay TH, Lim MK. Education and myopia in 110,236 young Singaporean males. Singapore Med $\mathcal{F} 1993$; 34:489-92.

3 Law NM, Chew SJ, Ritch R. Survey of refraction in a Chinese population shows that myopia severity can be
predicted from its age of onset. Invest Ophthalmol Vis Sci 1992;33(suppl):S709.

4 Wu HM, Yap EPH, Seet B, et al. Report on the study of myopia and its impact in a cohort of Singapore Armed Forces enlis-

tees. Singapore: Defence Medical Research Institute, 1998.
5 Lim HC, Quah BL, Balakrishnan V, et al. Vision screening Lim HC, Quah BL, Balakrishnan V, et al. Vision screening
of four-year old children in Singapore. Singapore Med $\mathfrak{f}$ of four-year old

6 Wu HM, Seet B, Yap EPH, et al. Does education explain racial differences in myopia prevalence? Optom Vis Sci 2001 (in press)

7 Wong TY, Foster P, Hee J, et al. Prevalence and risk factors for refractive errors in adult Chinese in Singapore. Invest Ophthalmol Vis Sci 2000;41:2486-94.

8 Saw SM, Katz J, Schein OD, et al. Epidemiology of myopia. Epidemiol Rev 1996;18:175-87.

9 Sperduto RD, Seigel D, Roberts J et al. Prevalence of myopia in the United States. Arch Ophthalmol 1983;101:405-7.

10 Katz J, Tielsch JM, Sommer A. Prevalence and risk factors for refractive errors in an adult inner city population. Invest for refractive errors in an adult inner

11 Wensor M, McCarty CA, Taylor HR. Prevalence and risk factors of myopia in Victoria, Australia. Arch Ophthalmol 1999;117:658-63. 
12 Wu SY, Nemesure B, Leske MC. Refractive errors in a black adult population: the Barbados Eye Study. Invest Ophthal adult population: the Barbados
mol Vis Sci 1999;40:2179-84

13 Chew SJ, Chia SC, Lee LKH. The pattern of myopia in young Singaporean men. Singapore Med $\mathcal{F}$ 1988;29:201-11.

14 AuEong KG, Tay TH, Lim MK. Race, culture and myopia in 110,236 young Singaporean males. Singapore Med $\mathcal{F}$ 1993;34:29-32.

15 Tan NW, Saw SM, Lam DS, et al. Temporal variations in myopia progression in Singaporean children within an academic year. Optom Vis Sci 2000;77:465-72.

16 Lin LLK, Chen CJ, Hung PT, et al. Nation-wide survey of myopia among school-children in Taiwan, 1986. Acta Ophmyopia among school-children in

17 Lin LLK, Shih YF, Tsai CB, et al. Epidemiologic study of ocular refraction among school-children in Taiwan in 1995. Optom Vis Sci 1999;76:275-81.

18 Goh WS, Lam CS. Changes in refractive trends and optical components of Hong Kong Chinese aged 19-39 years. Ophthalmic Physiol Opt 1994;14:378-82.

19 Hosaka A. Population studies - myopia experience in Japan Acta Ophthalmol 1988;185(suppl):37-40.

20 Matusumaru H, Hirai H. Prevalence of myopia and refractive changes in students from 3 to 17 years of age. Surv Ophthalmol 1999;44(suppl):S109-15.

21 Singapore Department of Statistics, Ministry of Trade and Industry. Yearbook of statistics, Singapore 1998. Singapore: Singapore National Printers, 1998.

22 Morita H, Funata $M$, Tokoro T. A clinical study of the development of posterior vitreous detachment in high myopia. Retina 1995;15:117-24

23 Curtin BJ. The myopias. Basic science and clinical management. Philadelphia: Harper and Row, 1985

24 Ito-Ohara M, Seko Y, Morita H, et al. Clinical course of newly developed or progressive patchy chorioretinal atrophy in pathological myopia. Ophthalmologica 1998;212: 23-9.

25 Avila MP, Weiter JJ, Jalkh AE, et al. Natural history of choroidal neovascularization in degenerative myopia. Ophchoroidal neovascularization

26 Pierro L, Camesasca FI, Mischi M, et al. Peripheral retinal changes and axial myopia. Retina 1992;12:12-27.

27 Mitchell P, Hourihan F, Sandbach J, et al. The relationship between glaucoma and myopia: the Blue Mountains Eye Study. Ophthalmology 1999;106:2010-15.

28 Oen FT, Lim TH, Chung MP. Contrast sensitivity in a large population. Ann Acad Med Singapore 1994;23:322-6.

29 Wu HM, Lim ATH, Seet B, et al. Spatial luminance contrast sensitivity function and dark adaptation in myopia. Invest Ophthalmol Vis Sci 1997;38(suppl):S2523.

30 Krumpaszky HG. Temporal trends in the etiology of blindness. Klin Monatsbl Augenheilkd 1997;210:A9-16.

31 Rosenberg T, Klie F. Current trends in newly registered blindness in Denmark. Acta Ophthalmol Scand 1996;74: 395-8.

32 See JL, Wong TY, Yeo KT. Trends in the pattern of blindness and major ocular diseases in Singapore and Asia Ann Acad Med Singapore 1998;27:540-6.

33 Rahmani B, Tielsch JM, Katz J, et al. The cause-specific prevalence of visual impairment in an urban population.
The Baltimore Eye Survey. Ophthalmology 1996;103: 1721-6.

34 Sommer A, Tielsch JM, Katz J, et al. Racial differences in the cause-specific prevalence of blind

$35 \mathrm{Bin} \mathrm{HH}$. Government can do more to curb myopia problem in schools. The Straits Times 1996; Oct 16:A30.

36 Tan KL. Beware of misleading ads on cures for myopia. The Straits Times 1999; June 16:A43.

37 Balakrishnan V. Facts, myths about myopia. The Straits Times 1999; July 16:A53.

38 Ling SL, Chen AJ, Rajan U, et al. Myopia in ten-year old children: a case-control study. Singapore Med f 1987;28 288-92.

39 Tay MTH, AuEong KG, Ng CY. Myopia and educationa attainment. Ann Acad Med Singapore 1992;21:785-91.

40 Zhan MZ, Saw SM, Hong RZ, et al. Refractive errors in Singapore and Xiamen, China - a comparative study in school children aged 6 to 7 years. Optom Vis $\mathrm{Sci}$ 2000;77:302-8

41 Rabin J. Correction of subtle refractive error in aviators. Aviat Space Environ Med 1996;67:161-4.

42 Kikukawa A, Yagura S, Akamatsu T. A 25-year prospective study of visual acuity in the Japan Air Self-Defense Force personnel. Aviat Space Environ Med 1999;70:447-50.

$43 \mathrm{Ng}$ BL. Medical selection of military pilots: a Republic of Singapore Air Force perspective. Ann Acad Med Singapore 1994;23:665-8.

44 Owsley C, Sloane ME. Contrast sensitivity, acuity and the perception of "real world" targets. $\mathrm{Br} f$ Ophthalmol 1987;71:791-6.

45 Ginsberg AP, Evans DW, Sekuler R, et al. Contrast sensitivity predicts performance in aircraft simulators. Am f Optom Physiol Opt 1982;59:105-9.

46 Turatto M, Facoetti A, Serra G, et al. Visual-spatial attention in myopia. Brain Res Cogn Brain Res 1999;8:36972.

47 Veljkovic D. The effect of refractive abnormalities in young people on their success in sharpshooting. Vojnosanit Pregl 1989;46:412-14.

48 Still DL, Temme LA. Eyeglass use by US Navy jet pilots: effects on night carrier landing performance. Aviat Space Environ Med 1992;63:273-75.
49 Wee TL, Chan WK, Tseng $\mathrm{P}$, et al. Excimer laser photorefractive keratectomy for the correction of myopia. Singapore Med f 1999;40:246-50.

50 Wong TY, Tielsch JM, Schein OD. Racial difference in the incidence of retinal detachment in Singapore. Arch Opthalmol 1999;117:379-83.

51 Tan DT, Lee CP, Lim ASM. Corneal ulcers in two institutions in Singapore: analysis of causative factors, organisms and antibiotic resistance. Ann Acad Med Singapore 1995;24:823-9.

52 Lim ASM, Tan DTH, Balakrishnan V, et al. 5-year plan for myopia research in Singapore [proposal to National Medical Research Councill. Singapore: Singapore Eye Research Institute, March 1999.

53 Curtin BJ. Physiologic vs pathologic myopia: genetics vs environment. Ophthalmology 1979;86:681-91.

54 Wallman J. Nature and nurture of myopia. Nature 1994;371: 201-2.

55 Mutti DO, Zadnik K, Adams AJ. Myopia: the nature versus nurture debate goes on. Invest Ophthalmol Vis Sci 1996;37: 952-7.

56 Chew SJ, Ritch R. Parental history and myopia-taking the long view. ҰAMA 1994;272:1255.

57 Yap M, Wu M, Liu ZM, et al. Role of heredity in the genesis of myopia. Ophthalmol Physiol Opt 1993;13:316-19.

58 Saw SM, Chua WH, Wu HM, et al. Myopia: geneenvironment interaction. Ann Acad Med Singapore 2000;29: $290-7$.

59 Chen CJ, Cohen BH, Diamond EL. Genetic and environmental effects on the development of myopia in Chinese twin children. Opthalmol Paediatr-Genet 1985;6:353-9.

60 Teikari JM, O'Donnell J, Kaprio J, et al. Impact of heredity in myopia. Hum Hered 1991;41:151-6.

61 Zadnik K, Satariano WA, Mutti DO, et al. The effect of parental history of myopia on children's eye size. $f A M A$ 1994;271:1323-7.

62 Young TL, Ronan SM, Drahozal LA, et al. Evidence that a locus for familial high myopia maps to chromosome $18 \mathrm{p}$. Am F Hum Genet 1998;63:109-19.

63 Olmedo MV, Munoz JI, Rodriguez-Cid MJ, et al. Two different genetic markers for high and low myopia. Eur $\mathcal{f}$ Ophthalmol 1992;2:196-9.

64 Wu HM, Yu XH, Yap EPH. Allelic association between trabecular meshwork-induced glucocorticoid response (TIGR) gene and severe sporadic myopia. Invest Ophthalmol Vis Sci 1999;40(suppl):S3148.

65 Wildsoet C, Wallman J. Choroidal and scleral mechanisms of compensation for spectacle lenses in chicks. Vis Res 1995;35:1175-94

66 Stone RA, Lin T, Laties AM. Muscarinic antagonist effects on experimental chick myopia. Exp Eye Res 1991;52: $755-8$.

67 Stone RA, Laties AM, Raviola E, et al. Increase in retinal vasoactive intestinal polypeptide after eyelid fusion in primates. Proc Natl Acad Sci 1988;85:257-60.

68 The Framingham Offspring Eye Study Group. Familial aggregation and prevalence of myopia in the Framingham Offspring Eye Study. Arch Ophthalmol 1996;114:326-32.

$69 \mathrm{Wu}$ MM, Edwards MH. The effect of having myopic parents: an analysis of myopia in three generations. Optom Vis Sci 1999;76:387-92.

70 Saw SM, Chia SE, Chew SJ. Relation between work and myopia in Singapore women. Optom Vis Sci 1999,76: 393-6.

71 Saw SM, Nieto FJ, Katz J, et al. Factors related to the progression of myopia in Singaporean children. Optom Vis Sci 2000;77:549-54

72 Saw SM, Nieto FJ, Katz J, et al. Distance, lighting and parental beliefs: understanding near work in epidemiologic studies of myopia. Optom Vis Sci 1999;76:355-62.

73 Saw SM, Nieto JF, Katz J, et al. Estimating the magnitude of close-up work in school-age children: a comparison of questionnaire and diary instruments. Ophthalmic Epidemiol 1999;6:291-301.

74 Chow YC, Dhillon B, Chew PTK, et al. Refractive errors in Singapore medical students. Singapore Med f 1990;31: $472-3$.

75 Baum S. Social transformation in the global city: Singapore. Urban Studies 1999;36:1095-117.

76 Khatri N. Emerging issues in strategic human resource management in Singapore. Int $\mathcal{f}$ Manpower 1999;20: 516-29.

77 Wilson DR, Keeney AH. Corrective measures for myopia. Surv Ophthalmol 1990;34:284-304.

78 Shih YF, Chen $\mathrm{CH}$, Chou AC, et al. Effects of different concentrations of atropine on controlling myopic children. $\mathcal{F}$ Ocul Pharmacol Ther 1999;15:85-90.

79 Fulk GW, Cyert LA. Can bifocals slow myopia progression? 7 Am Optom Assoc 1996;67:749-54.

80 Leung JT, Brown B. Progression of myopia in Hong Kong school-children is slowed by wearing progressive lenses. Optom Vis Sci 1999;76:346-54

81 Khoo CY, Chong J, Rajan U. A 3-year study on the effect of RGP contact lenses on myopic children. Singapore Med $\mathcal{F}$ 1999;40:230-7.

82 Jensen $\mathrm{H}$. Timolol maleate in the control of myopia: a preliminary report. Acta Ophthalmol 1988;185(suppl): 128-9.

83 Gilmartin B, Gray LS, Winn B. The amelioration of myopia using biofeedback of accommodation: a review. Ophthalmol Physiol Opt 1991;11:304-13. 
84 Shih YF, Lin LL, Hwang CY, et al. The effects of qi-qong ocular exercise on accommodation. Clin f Physiol 1995;38: ocular exe.

85 Thai TF. Programmes and measures to reduce and prevent myopia [policy paper]. Singapore: School Health Services, Ministry of Health, 1998

86 National Committee of Ophthalmology. Clinical practice guidelines: contact lens complications. Singapore: Ministry of Health, 2000

87 National Committee of Ophthalmology. Clinical practice guidelines: laser refractive surgery. Singapore: Ministry of Health, 1999.
88 Chew SJ, Beuerman RW. Control of cornea wound-healing and myopia by in vivo and in vitro inhibition of scleral and cornel fibroblast proliferation by muscarinic antagonists.

89 Wong TY, Foster PJ, Ng TP, et al. Variations in ocular biometry in an adult Chinese population in Singapore. The Tanjong Pagar Survey. Invest Ophthalmol Vis Sci 2001;42: 73-80.

$90 \mathrm{Lim}$ WK, Theng J, Chew SJ. Operational application of continuous wear contact lens in seamen for naval operations. Invest Ophthalmol Vis Sci 1999;40(suppl): S2286.

\section{1st Asia Pacific Forum on Quality Improvement in Health Care}

\section{Three day conference}

\section{Wednesday 19 to Friday 21 September 2001 \\ Sydney, Australia}

We are delighted to announce this forthcoming conference in Sydney. Authors are invited to submit papers (call for papers closes on Friday 6 April), and delegate enquiries are welcome.

The themes of the Forum are:

- Improving patient safety

- Leadership for improvement

- Consumers driving change

- Building capacity for change: measurement, education and human resources

- The context: incentives and barriers for change

- Improving health systems

- The evidence and scientific basis for quality improvement.

Presented to you by the BMJ Publishing Group (London, UK) and Institute for Healthcare Improvement (Boston, USA), with the support of the the Commonwealth Department of Health and Aged Care (Australia), Safety and Quality Council (Australia), NSW Health (Australia), and Ministry of Health (New Zealand).

For more information contact: quality@bma.org.uk or fax +44 (0)20 73836869 